\title{
Identification of TRPM6 and TRPM7 expression changes in response to a diet supplemented with inulin in porcine kidney
}

\author{
Paulina Robak $^{1}$, Małgorzata Ożgo ${ }^{1}$, Katarzyna Michałek ${ }^{1}$, Agnieszka Kolasa-Wołosiuk ${ }^{2}$, \\ Marcin Taciak $^{3}$, Marcin Barszcz ${ }^{3}$, and Marta Marynowska ${ }^{1}$ \\ ${ }^{1}$ Department of Physiology, Cytobiology and Proteomics, Faculty of Biotechnology and Animal Husbandry, \\ West Pomeranian University of Technology in Szczecin, Doktora Judyma 6, 71-466 Szczecin, Poland \\ ${ }^{2}$ Department of Histology and Embryology, Pomeranian Medical University, Powstańców Wielkopolskich 72 \\ Avenu, 70-111 Szczecin, Poland \\ ${ }^{3}$ Department of Monogastric Nutrition, The Kielanowski Institute of Animal Physiology and Nutrition, \\ Polish Academy of Sciences, Instytucka 3, 05-110, Jabłonna, Poland
}

Correspondence to: Małgorzata Ożgo (malgorzata.ozgo@zut.edu.pl)

Received: 24 March 2016 - Revised: 1 June 2016 - Accepted: 7 June 2016 - Published: 14 June 2016

\begin{abstract}
Magnesium is the fourth most abundant mineral element in vertebrates and the second most common intracellular cation. Recently identified $\mathrm{Mg}^{2+}$-specific channels - TRPM6 and TRPM7 - have been shown to be essential for whole-body and cellular $\mathrm{Mg}^{2+}$ homeostasis. The aim of the study was to determine the effect of inulin on the expression of TRPM6 and TRPM7 in the renal cortex and medulla of growing pigs. The study was carried out on 16 Danbred $\times$ Duroc castrated male piglets fed a cereal-based diet without inulin or with $2 \%$ addition of inulin from chicory root from the 10th day of life. In pigs fed a diet with inulin, TRPM6 expression was greater in both the renal cortex and medulla compared to the control group. The expression of TRPM7 in both the renal cortex and medulla in the control group and in piglets fed a diet enriched with inulin was relatively stable. To our knowledge, this is the first study aimed at the identification of TRPM6 and TRPM7 in the kidneys of pig. It is proposed that inulin addition to fodder resulted not only in a magnesium absorption increase, but also, due to prolonged low plasma $\mathrm{Mg}$ concentration of examined piglets, renal magnesium retention. Therefore, higher magnesium reabsorption via increased TRPM6 expression in the kidney was probably observed in order to supplement deficiencies of this element. Diet-unresponsive expression of TRPM7 supports the concept that this channel is not involved in the extracellular magnesium homeostasis.
\end{abstract}

\section{Introduction}

Magnesium is the fourth most abundant mineral element in vertebrates and the second most common intracellular cation that is essential, especially as a cofactor of many enzymes. The magnesium ions play an important role in all major cellular processes such as energy metabolism, DNA replication, transcription and protein synthesis. Magnesium is mainly involved in bone formation, neuromuscular stability and muscle contraction (Quamme, 2008; Jahnen-Dechent and Ketteler, 2012). With respect to production and pig welfare, the consumption of the recommended magnesium amount in a diet by pigs was shown to improve pork quality, specifically the color and fluid loss. Sufficient Mg intake may positively affect the behavior of animals and decrease the stress sensitivity of pigs (Lipiński et al., 2011).

About $99 \%$ of the total body magnesium is located in bone, muscles and non-muscular soft tissues. The remaining amount is found in red blood cells and extracellular fluids, primarily blood plasma (Quamme and Rouffignac, 2000; Jahnen-Dechent and Ketteler, 2012). Magnesium homeostasis is regulated by intestinal absorption of available dietary magnesium, storage in bone and renal excretion of urinary magnesium (Konrad et al., 2004; Quamme, 2008; Jahnen- 
Dechent and Ketteler, 2012). The kidneys are crucial in magnesium homeostasis as these organs provide the most sensitive control for serum-magnesium balance. Magnesium absorption through the nephron segments differs from that of most other ions. The main reabsorption site is not the proximal tubule, but the thick ascending limb of the loop of Henle, where $60-70 \%$ of the total magnesium filtered at the glomerulus is reabsorbed (Quamme and Rouffignac, 2000; Jahnen-Dechent and Ketteler, 2012). There, transepithelial magnesium movement is mostly paracellular and passive. Approximately $10-15 \%$ of the filtered magnesium is absorbed in the distal tubules. In the distal convoluted tubule and connecting segments magnesium absorption is transcellular and active (Dai et al., 2001; Quamme and Rouffignac, 2000), but little is known about the proteins involved in this transport.

Recently identified $\mathrm{Mg}^{2+}$-specific channels - TRPM6 and TRPM7 - have been shown to be essential for whole-body and cellular $\mathrm{Mg}^{2+}$ homeostasis (Schlingmann and Gudermann, 2005; Pham et al., 2014). The TRP protein family is a group of voltage-independent cation-permeable channels expressed in most mammalian cells (Hsu et al., 2007; de Feo, 2009). The transient receptor potential melastatin (TRPM) cation channels differ significantly from other TPR members regarding domain structure, cation permeation characteristics and activation mechanisms (Chubanov et al., 2004; Schlingmann et al., 2007). TRPM6 and its closest homologue TRPM7 consist of six membrane-spanning domains that form the channel pore and large intracellular aminoterminal and carboxy-terminal domains (van der Wijst et al., 2014). TRPM6 is specifically localized along the apical membrane of the renal distal convoluted tubule. There, it regulates $\mathrm{Mg}^{2+}$ transport and alters whole-body magnesium homeostasis by controlling urinary excretion (Seo and Park, 2008; Pham et al., 2014). This channel is constitutively open but tightly regulated by intracellular $\mathrm{Mg}^{2+}$ concentration (van der Wijst et al., 2014). TRPM7 is ubiquitously expressed among tissues and is involved in cellular $\mathrm{Mg}^{2+}$ homeostasis (Romani, 2011). Like TRPM6, TRPM7 is highly sensitive to intracellular $\mathrm{Mg}^{2+}$. Moreover, TRPM7 was shown to be involved in several cellular processes, such as cell cycle regulation, cell growth, cell proliferation and cell death (Muallem and Moe, 2007; Xie et al., 2011).

In pigs, $\mathrm{Mg}^{2+}$ serum concentration ranges between 1.11 and $1.52 \mathrm{mmol} \mathrm{L}^{-1}$ (Kaneko et al., 2008). In order to maintain these levels, a daily magnesium intake of 400 and $500 \mathrm{ppm}$ of the total ration is recommended for growing pigs (Mayo et al., 1959). Of the total magnesium consumed, approximately $30-50 \%$ is absorbed in the gut (de Baaij et al., 2012). Pigs were reported to absorb magnesium mainly in the ileum and the colon (Yoshiki, 2007). Intestinal absorption occurs through passive paracellular transport between the epithelial cells and active transcellular transport, mediated by TRPM6 and 7 (Konrad et al., 2004; Quamme, 2008). Intestinal absorption was shown to be regulated more by magne- sium status than by dietary magnesium intake. The lower the magnesium concentration in blood, the more magnesium is absorbed in the intestine; thus, absorption may be high at a low dietary intake (Jahnen-Dechent and Ketteler, 2012).

Intestinal absorption of minerals, including iron, magnesium and calcium, may be affected by dietary fiber (ScholzAhrens et al., 2001; Yasuda et al., 2006; Samanta et al., 2013). Among indigestible carbohydrates, inulin is of particular interest due to its potential health-promoting activity. Inulin-type fructans targets a range of different physiological functions, starting from intestine performance and microflora activity to mineral absorption, lipid homeostasis and immunity. Experiments conducted on piglets demonstrated that dietary supplementation with inulin stimulates the growth of bifidobacteria and lactobacilli, thereby suppressing pathogens in the lumen and mucosa of gut segments (Verdonk et al., 2005; Xu et al., 2005). Fiber-rich food has a favorable effect on lipid metabolism, especially due to inhibition of de novo fatty acid synthesis. Prebiotics reduce plasma total cholesterol and LDL cholesterol (Beylot, 2005; Cieślik et al., 2005; Roberfroid, 2007), also in pigs (Grela et al., 2014). Inulin is a plant storage carbohydrate which is a mixture of fructose oligomers and polymers that are resistant to mammalian digestive enzymes due to $\beta(2-1)$ linkages between fructose units. Intestinal bacteria are able to degrade fructans, leading to changes in the intestinal environment that may facilitate mineral absorption (Roberfroid, 2005a).

Due to the importance of magnesium in piglet nutrition and breeding, it is justified to confirm the potential contribution of inulin to improving magnesium reabsorption in kidneys and thereby its retention in organism. Therefore, the aim of the study was to determine the effect of inulin on the expression of TRPM6 and TRPM7 in the renal cortex and medulla of growing pigs. To the best of our knowledge, this is the first report that shows precise TRPM6 and $7 \mathrm{im}-$ munolocalization in the porcine kidneys. Moreover, in terms of anatomy, physiology and genetics, pigs are more similar to humans compared to other animals (Mandel et al., 2004; Bendixen et al., 2010; Luo et al., 2014). As opposed to the unipapillary structure of the rodent kidney, pigs have multipapillary kidneys similar to humans. The size of the kidney, the collecting system and the predominantly short-looped nephrons closely resemble the anatomical and physiological features of the human kidney (Sampaio et al., 1998; EskildJensen et al., 2007; Bagetti Filho et al., 2008). In view of the above, our study may be also useful for designing further studies in human medicine.

\section{Materials and methods}

\subsection{Experimental animals and diets}

The experimental protocol was approved (No. 30/2010) by the Third Local Animal Experimentation Ethics Commission (Warsaw University of Life Sciences - SGGW, War- 
saw Poland) in accordance with the principles of the European Union and Polish Law on Animal Protection. The study was carried out on 16 Danbred $\times$ Duroc castrated male piglets fed a cereal-based diet without inulin or with $2 \%$ addition of inulin with an average degree of polymerization of 23 (Inulin Orafti ${ }^{\circledR}$ HPX, BENEO GmbH) from chicory root from the 10th day of life. Experimental diets consisted of wheat $(45.8 \%)$, barley $(20 \%)$, corn starch $(4 \%$ in the control diet and $2 \%$ in inulin-supplemented diet), full-fat soybeans $(5.9 \%)$, whey $(9.7 \%)$, fish meal $(4 \%)$, spray-dried plasma $(4 \%)$, soybean oil $(3.4 \%)$, calcium formate $(0.3 \%)$, pasture chalk $(0.5 \%)$, calcium phosphate $(0.6 \%)$, pasture salt $(0.07 \%)$, L-lysine $(0.6 \%)$, DL-methionine $(0.2 \%)$, Lthreonine $(0.26 \%)$, L-tryptophan $(0.09 \%)$, premix $(0.4 \%)$ and aroma $(0.1 \%)$. The diet contained $20 \%$ crude protein and $14.3 \mathrm{MJ} \mathrm{kg}^{-1}$ metabolizable energy.

Until the day of weaning, piglets were kept with their sows (four litters per group) in farrowing pens on a farm. At 28th day of life piglets were weaned, weighed and then two animals of an average body weight of $7.9 \mathrm{~kg}$ were chosen from each litter and transported to the experimental facility. The animals were placed in pens of 4 pigs each (two pens per group), in a room with $25^{\circ} \mathrm{C}, 12 \mathrm{~h}-12 \mathrm{~h}$ dark-light cycle and free access to feed and water. After 40 days of feeding pigs were sacrificed by electric shock and blood samples were taken into heparinized tubes during exsanguination. Blood plasma was obtained by centrifugation $(3000 \mathrm{rpm}, 10 \mathrm{~min}$, $4^{\circ} \mathrm{C}$ ) and stored at $-40^{\circ} \mathrm{C}$. Kidneys were excised and cut into pieces. Tissue samples for western blot analysis were snap-frozen in liquid nitrogen and stored at $-80^{\circ} \mathrm{C}$, whereas samples for immunohistochemistry were washed twice with an ice-cold $0.9 \% \mathrm{NaCl}$ solution and subsequently twice with the ice-cold Krebs-HEPES buffer (20 mM, pH 7.4) and fixed in $4 \%$ formalin.

\section{2 sodium dodecyl sulfate polyacrylamide gel electrophoresis (SDS-PAGE) and western blot}

The tissue samples were placed in the lysis buffer $(5 \mathrm{M}$ urea, $2 \mathrm{M}$ thiourea, $4 \% 3-((3-$ Cholamidopropyl)dimethylammonio)-1-propanesulfonate

(CHAPS), $40 \mathrm{mM}$ Tris, $0.2 \%$ ampholytes $\mathrm{pH} 3-10$, nuclease $1: 1000)$ containing a protease inhibitor cocktail (1:100; Sigma-Aldrich). Afterwards, the tissue samples were frozen in liquid nitrogen and were homogenized using the Tissue Lyser (QIAGEN). The homogenates were centrifuged at $20800 \times g$ for $15 \mathrm{~min}$ at $4{ }^{\circ} \mathrm{C}$. The samples were warmed to $37^{\circ} \mathrm{C}$ and loaded on the $12 \%$ polyacrylamide gels and run for $120 \mathrm{~min}$ at $100 \mathrm{~V}$. The proteins were then electrotransferred $(12 \mathrm{~V}, 14 \mathrm{~min})$ to PVDF membranes. The membranes were blocked with $5 \%$ non-fat milk in phosphate-buffered saline with tween ${ }^{\circledR}$ (PBS-T; $80 \mathrm{mM} \mathrm{Na}_{2} \mathrm{HPO}_{4}, 20 \mathrm{mM} \mathrm{NaH}_{2} \mathrm{PO}_{4}, 100 \mathrm{mM} \mathrm{NaCl}$ and $0.1 \%$ Tween $20, \mathrm{pH} 7.5$ ) for $1 \mathrm{~h}$ and incubated overnight at $4{ }^{\circ} \mathrm{C}$ with anti-TRPM6 and TRPM7 rabbit polyclonal antibodies (orb38901 and orb38899, Bioryt) diluted $1: 1000$, followed by incubation with secondary anti-rabbit (120P Serotec) horseradish peroxidase-conjugated antibodies. The labeling was visualized by the enhanced chemiluminescence system (ECL plus) and exposure to a CCD camera (Versadoc 4000MP, Bio Rad). The densitometry values and band optical density (OD) was evaluated with Quantity One software. The expression of TRPM6 and TRPM7 were normalized against $\beta$-actin, which was used as an internal control.

\subsection{Immunohistochemistry}

The kidneys were embedded in paraffin blocks and sliced into $2-3 \mu \mathrm{m}$ thick sections on a rotary microtome. Preparations were deparaffinized in xylene, hydrated through graded ethanol concentrations to water and used for further immunohistochemical staining. In order to expose the epitopes, the sections were boiled twice in a microwave oven ( $700 \mathrm{~W}$ for 4 and $3 \mathrm{~min}$ ) in $10 \mathrm{nM}$ citrate buffer ( $\mathrm{pH} 6.0$ ). Once cooled and washed with PBS, the slides were incubated for $60 \mathrm{~min}$ at room temperature with primary anti-TPRM6 and anti-TRPM7 rabbit polyclonal antibodies (orb38901 and orb38899, Bioryt; final dilution 1:500). To visualize the antigen-antibody complex, a Dako LSAB+System-HRP (Code K0679; DakoCytomation, Glostrup, Denmark) was used, based on the reaction of avidin-biotin-horseradish peroxidase with $3,3^{\prime}$-(DAB) as a chromogen in conformity with the included staining procedure instruction. Sections were washed in distilled $\mathrm{H}_{2} \mathrm{O}$ and counterstained with hematoxylin. For a negative control, specimens were processed in the absence of a primary antibody. Positive staining was defined microscopically (Leica DM5000B, Wetzlar, Germany) by visual identification of brown pigmentation.

\subsection{Blood plasma magnesium concentration}

Magnesium concentration in blood plasma was determined colorimetrically based on reaction with calmagite in an alkaline solution, using ready-to-use ELITech reagents (ELITech Group, Puteaux, France). All steps and absorbance measurements at $500 \mathrm{~nm}$ were performed on a MAXMAT PL multidisciplinary diagnostic platform (Erba Diagnostics France SARL).

\subsection{Statistical analysis}

Mean values and standard deviations were calculated. The resulting data were analyzed by Student's $t$ test using Statistica, $10.0^{\mathrm{TM}}$ in order to test significance of differences.

\section{Results}

As seen in Table 1, magnesium concentration in blood plasma ranged from 0.56 to $0.71 \mathrm{mmol} \mathrm{L}^{-1}$ in control pigs 

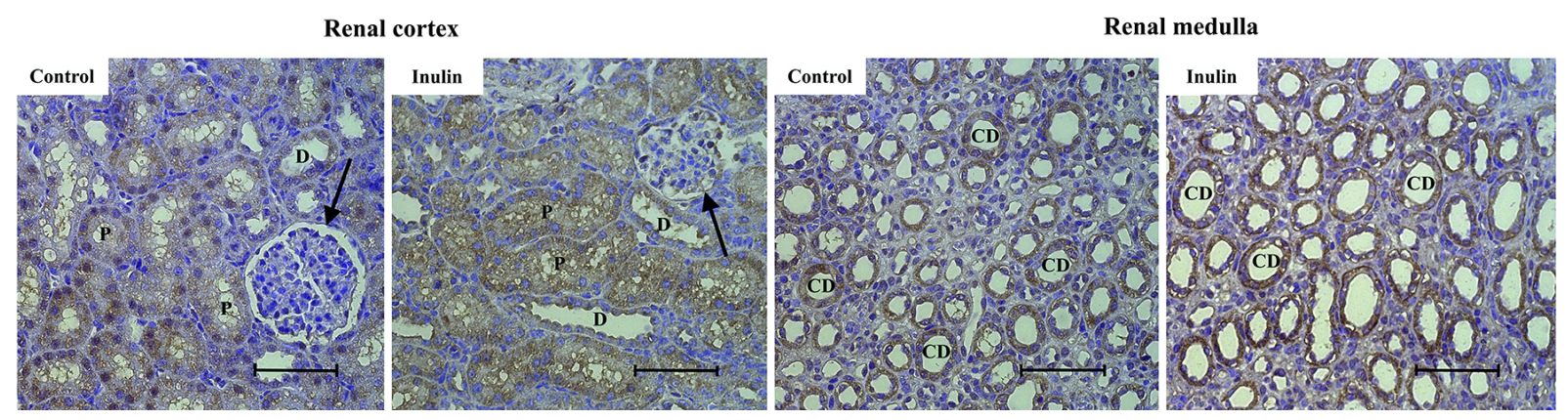

Figure 1. Immunolocalization and immunoexpression of TRPM6 in the renal cortex and medulla of the control group and pigs fed a diet supplemented with $2 \%$ inulin. The letters and markers on microphotography indicate the following: D - distal tubules; $\mathrm{P}$ - proximal tubules; black arrow - glomerulus; $\mathrm{CD}-$ collecting ducts. Bar $=50 \mu \mathrm{m}$.
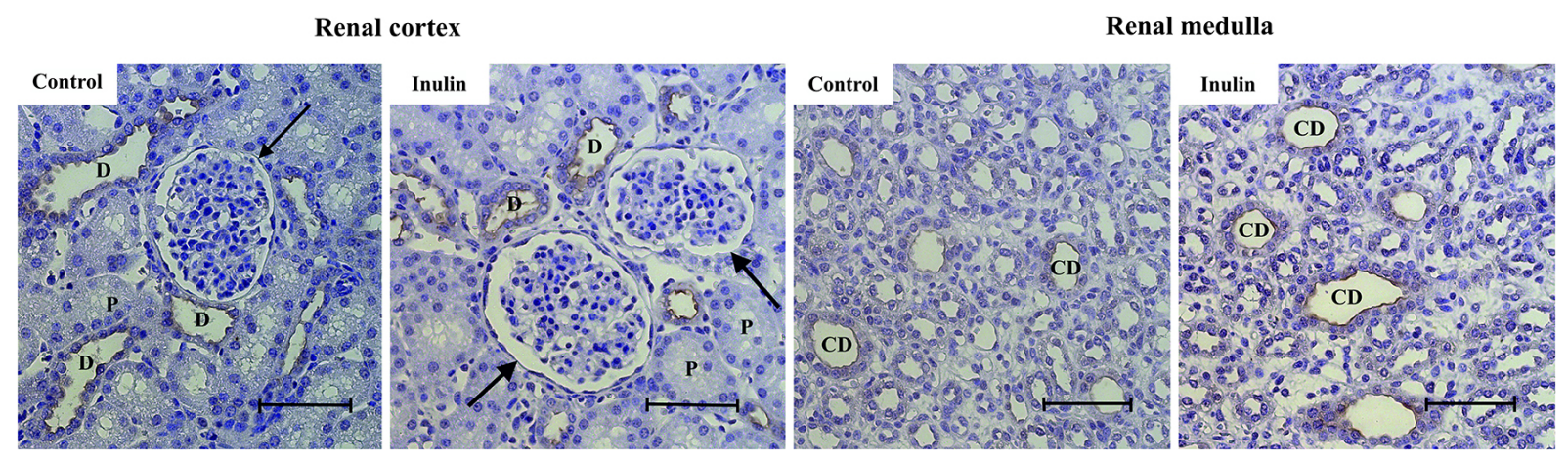

Figure 2. Immunolocalization and immunoexpression of TRPM7 in the renal cortex and medulla of the control group and pigs fed a diet supplemented with $2 \%$ inulin. The letters and markers on microphotography indicate the following: D - distal tubules; P - proximal tubules; black arrow - glomerulus; $\mathrm{CD}$ - collecting ducts. Bar $=50 \mu \mathrm{m}$.

and from 0.62 to $0.68 \mathrm{mmol} \mathrm{L}^{-1}$ in animals fed a diet containing inulin. The average $\mathrm{Mg}^{2+}$ concentrations were 0.64 and $0.66 \mathrm{mmol} \mathrm{L}^{-1}$ in the control pigs and experimental animals, respectively, and no statistically significant difference between these two groups was found.

Figure 1 shows the immunolocalization and immunoexpression of TRPM6 in the renal cortex and medulla of the control group and pigs fed a diet supplemented with $2 \%$ inulin. TRPM6 was found in the proximal and distal tubule of the renal cortex and in the collecting ducts of the renal medulla. It was mainly visible in the apical plasma membrane of those cells. In pigs fed a diet with inulin, TRPM6 expression was stronger in both the renal cortex and medulla compared to the control group. Figure 2 demonstrates the immunolocalization and immunoexpression of TRPM7 in the renal cortex and medulla of the control and experimental pigs. TRPM7 was found in the distal tubules of the renal cortex and in the collecting ducts of renal medulla. In all tested animals TRPM7 was mainly visible in the apical plasma membrane. The expression of TRPM7 in both the renal cortex and medulla in the control group and in piglets fed a diet enriched with inulin was comparable.

As seen in Fig. 3, feeding an inulin-enriched diet significantly $(P<0.05)$ increased the expression of TRPM6 in the
Table 1. Magnesium concentration in the blood plasma of the control group and animals fed a diet supplemented with inulin.

\begin{tabular}{lrr}
\hline & \multicolumn{2}{c}{$\mathrm{Mg}^{2+}$ concentration $\left[\mathrm{mmol} \mathrm{L}^{-1}\right]$} \\
\cline { 2 - 3 } No. & Control group & Inulin-fed group \\
\hline 1 & 0.69 & 0.65 \\
2 & 0.56 & 0.66 \\
3 & 0.67 & 0.66 \\
4 & 0.65 & 0.66 \\
5 & 0.65 & 0.62 \\
6 & 0.71 & 0.67 \\
7 & 0.63 & 0.68 \\
8 & 0.59 & 0.65 \\
\hline
\end{tabular}

kidneys, both in the renal cortex and medulla. The expression of this protein in the renal cortex in the group of the piglets fed the modified diet was 1.3 -fold higher than in the control group. TRPM6 expression in the renal medulla in the piglets fed a diet supplemented with inulin was about 2.7 fold higher than in the pigs in the control group. The expression of TRPM7 in both the renal cortex and medulla in all tested animals was comparable and unaffected by inulin 

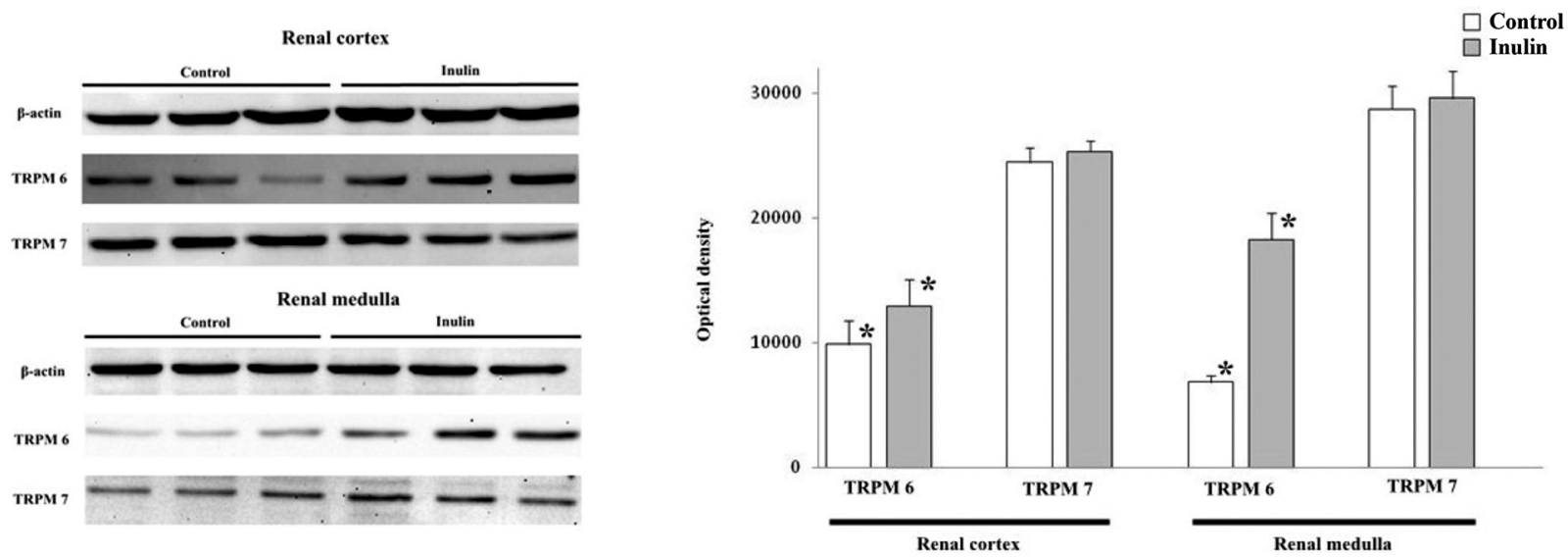

* Significance of differences $(\mathrm{P}<0.005)$ between the expression of TRPM6 in the renal cortex and medulla in the control group and in the pigs fed diet supplemented with $2 \%$ inulin.

Figure 3. Representative results of immunoblotting analysis of TRPM6 and TRPM7 in the renal cortex and medulla of pigs.

(Fig. 3). The analysis of obtained results shows that in all pigs fed a standard diet the labeling of TRPM6 was almost 1.4fold more intensive in the renal cortex than in the medulla.

\section{Discussion}

To our knowledge, this is the first study aimed at the identification of TRPM6 and TRPM7 in the kidneys of pig. Here, we demonstrate the localization of TRPM6 and TRPM7 channels along a specific region of the nephron and collecting ducts, as well as expression changes of these proteins under the influence of dietary supplementation with inulin.

TRPM6 was found in the proximal and distal tubule of the renal cortex and in the collecting ducts of the renal medulla. TRPM6 was mainly visible in the apical plasma membrane of those cells. Previous studies in rodents (Voets et al., 2004; Groenestege et al., 2006; Rondón et al., 2008b) and humans (Schlingmann et al., 2002) indicated that TRPM6 is localized exclusively in the distal convoluted tubules. In contrast, Schlingmann et al. detected TRPM6 mRNA in the proximal and distal convoluted tubules as well as in the collecting ducts of rat (Schlingmann et al., 2002). TRPM6 expression was increased in both the renal cortex and medulla in piglets fed with inulin compared with the control group.

TRPM7 was expressed along the apical membrane of the distal tubules of renal cortex and in the collecting ducts of renal medulla. Previously, Chubanov et al. (2004) reported TRPM7 localization in the nephron of rat kidneys. These authors detected TRPM7 mRNA in all nephron segments tested, including glomeruli, proximal convoluted tubule, descending thin limb, ascending thin limb, medullary thick ascending limb, cortical thick ascending limb, distal convoluted tubule, as well as connecting tubule/cortical collecting duct, outer medullary collecting duct and inner medullary collecting duct (Chubanov et al., 2004). The expression of
TRPM7 in the renal cortex and medulla in both groups of pigs was comparable, without statistically significant differences. The diet-unresponsive expression of TRPM7 could support the concept that this channel is not involved in the extracellular magnesium homeostasis. These results are in accordance with the study conducted on mice, where dietary magnesium did not alter TRPM7 mRNA expression in the kidneys (Quamme, 2008; Rondón et al., 2008b).

Magnesium is an essential macro-mineral which is required for numerous functions in the organism. Growing animals exhibit higher magnesium requirements, since many of the physiological processes involving magnesium are more intensive during this specific period of life. All examined animals demonstrated plasma $\mathrm{Mg}^{2+}$ concentrations below the reference value of $1.11-1.52 \mathrm{mmol} \mathrm{L}^{-1}$. However, piglets did not present any signs of magnesium deficiency. The daily magnesium intake provided with fodder was sufficient (magnesium content was 1639 and $1584 \mathrm{mg} \mathrm{kg}^{-1}$ in control fodder and inulin supplemented feed, respectively). The extraand intracellular magnesium level is very variable, a fact that cannot be attributed either to methodological errors or to basic instability but is mostly due to important interindividual differences. Some genetic factors are involved in regulation of the plasma magnesium concentration. Extra- and intracellular magnesium levels were shown to be genetically controlled in humans and in mice (Henrotte, 1993; Henrotte et al., 1997; Ozgo et al., 2007).

Magnesium reabsorption in the distal convoluted tubule is tightly regulated by the plasma $\mathrm{Mg}^{2+}$ level (de Baaij et al., 2012). Upregulation of TRPM6 in the kidney can be explained by the lower plasma $\mathrm{Mg}^{2+}$ concentration. In the case of $\mathrm{Mg}^{2+}$ insufficiency, TRPM6 channels may facilitate maximal $\mathrm{Mg}^{2+}$ reabsorption. Therefore, a high expression of TRPM6 is an expected homeostatic response, as these channels are considered to be key regulators of $\mathrm{Mg}^{2+}$ homeosta- 
sis. Moreover, higher TRPM6 expression in the renal cortex of all tested animals may be associated with more intensive reabsorption processes, which occur within this part of the kidney in growing animals. As reported by Quamme and Rouffignac (2010), of the total load of magnesium filtered at the glomerulus, the proximal tubule reabsorbs approximately $10-15 \%$ in adults. By contrast, the proximal tubule of young animals reabsorbs about $50-60 \%$ of filtered magnesium (Quamme and Rouffignac, 2010).

Coudray et al. postulated that active transport of magnesium in the gut is important under conditions of a low dietary supply of magnesium. It was demonstrated that $\mathrm{Mg}^{2+}$ absorption in rats linearly increased with increasing dietary magnesium up to the required level (Caudray et al., 2002). Insufficient magnesium status could be a stimulus for an activation of TRPM6 channels in the kidney and thereby more intensive $\mathrm{Mg}^{2+}$ reabsorption.

Several studies in rodents demonstrated that dietary inulintype fructans improves magnesium absorption (Delzenne et al., 1995; Younes et al., 2001; Demigné et al., 2008), retention and its incorporation into bones (Caudray et al., 2002; Demigné et al., 2008). There are several proposed explanations for the beneficial effect of inulin-type fructans on mineral absorption and bioavailability, i.e., a higher water content in the large intestine due to an osmotic effect, acidification of the cecal contents and increased solubility in intestinal lumen by short-chain fatty acids (SCFA), and greater absorptive surface due to hypertrophy of the mucosa (Tahiri et al., 2001; Roberfroid, 2005b; Rondón et al., 2008b).

Previous experiments conducted on mice indicated that dietary $\mathrm{Mg}$ deficiency and hypomagnesemia result in a significant upregulation of TRPM6 channels in the kidneys, whereas a Mg-enriched diet decreases TRPM6 expression (Groenestege et al., 2006; Rondón et al., 2008a; van Angelen et al., 2013). However, upregulation of TRPM6 in pigs fed a diet supplemented with inulin does not necessarily indicate that inulin did not improve the bioavailability of magnesium. Due to the fact that pigs exhibited a low plasma Mg level and their magnesium requirement was higher in the period of intensive growth, it is proposed that increased TRPM6 expression, and thereby higher $\mathrm{Mg}$ reabsorption in the kidney, was the physiological response in order to supplement deficiencies in this element. This is consistent with a previous study on mice, where it was concluded that magnesium depletion increases TRPM6 mRNA expression and protein levels in the kidney (Groenestege et al., 2006).

Moreover, prolonged low plasma $\mathrm{Mg}$ concentration does not necessarily imply that there was no improvement in mineral absorption and bioavailability associated with inulin consumption. We suggest that magnesium provided with the feed and absorbed along the length of the nephron and collecting ducts system could have been utilized immediately, for example absorbed in bones or used for enzymatic processes.
In addition to dietary magnesium, there are other factors influencing the TRPM6 expression level including hormones (e.g., epidermal growth factor (EGF) (Xie et al., 2011), estrogen (Groenestege et al., 2006; Xie et al., 2011), aldosterone (Groenestege et al., 2006), angiotensin II (Pham et al., 2014), bradykinin (Pham et al., 2014) and insulin (Pham et al., 2014)), the acid-base balance and extracellular $\mathrm{pH}$ (Li et al., 2006), which should also be taken into consideration with regard to the possible effect of inulin.

There is still much to be discovered regarding the function and regulation of TRPM6 and TRPM7 channels, as well as their biological importance in magnesium handling. In relation to the biological importance of this mineral element, future research in this field is required to uncover mechanisms governing $\mathrm{Mg}^{2+}$ transport.

Edited by: S. Maak

Reviewed by: two anonymous referees

\section{References}

Bagetti Filho, H. J., Pereira-Sampaio, M. A., Favorito, L. A., and Sampaio, F. J.: Pig kidney: anatomical relationships between the renal venous arrangement and the kidney collecting system, J. Urol., 179, 1627-1630, 2008.

Bendixen, E., Danielsen, M., Larsen, K., and Bendixen, C.: Advances in porcine genomics and proteomics-a toolbox for developing the pig as a model organism for molecular biomedical research, Brief Funct. Genomics, 9, 208-219, 2010.

Beylot M.: Effects of inulin-type fructans on lipid metabolism in man and in animal models, Br. J. Nutr., 93, 163-168, 2005.

Chubanov, V., Waldegger, S., Mederos y Schnitzler, M., Vitzthum, H., Sassen, M. C., Seyberth, H. W., Konrad, M., and Gudermann, T.: Disruption of TRPM6/TRPM7 complex formation by a mutation in the TRPM6 gene causes hypomagnesemia with secondary hypocalcemia, Proc. Natl. Acad. Sci. USA, 101, 28942899, 2004.

Cieślik E., Kopeć A., PawełM., and Pisulewski M.: Effects of fructooligosaccharides and long-chain inulin on serum lipids in rats, Pol. J. Food Nutr. Sci., 14/55, 437-441, 2005.

Coudray, C., Feillet-Coudray, C., Grizard, D., Tressol, J. C., Gueux, E., and Rayssiguier, Y.: Fractional intestinal absorption of magnesium is directly proportional to dietary magnesium intake in rats, J. Nutr., 132, 2043-2047, 2002.

Dai, L. J., Ritchie, G., Kerstan, D., Kang, H. S., Cole, D. E., and Quamme, G. A.: Magnesium transport in the renal distal convoluted tubule, Physiol. Rev., 81, 51-84, 2001.

De Baaij, J. H., Hoenderop, J. G., and Bindels, R. J.: Regulation of magnesium balance: lessons learned from human genetic disease, Clin. Kidney J., 5, i15-i24, 2012.

De Feo, M. L.: Magnesium disorders: clinical experience and review of the literature, Clin. Cases Miner. Bone Metab., 6, 220222, 2009.

Delzenne, N., Aertssens, J., Verplaetse, H., Roccaro, M., and Roberfroid, M.: Effect of fermentable fructo-oligosaccharides on mineral, nitrogen and energy digestive balance in the rat, Life Sci., 57, 1579-1587, 1995. 
Demigné, C., Jacobs, H., Moundras, C., Davicco, M. J., Horcajada, M. N., Bernalier, A., and Coxam, V.: Comparison of native or reformulated chicory fructans, or nonpurified chicory, on rat cecal fermentation and mineral metabolism, Eur. J. Nutr., 47, 366-374, 2008.

Eskild-Jensen, A., Paulsen, L. F., Wogensen, L., Olesen, P., Pedersen, L., Frøkiaer, J., and Nyengaard, J. R.: AT1 receptor blockade prevents interstitial and glomerular apoptosis but not fibrosis in pigs with neonatal induced partial unilateral ureteral obstruction, Am. J. Physiol. Renal. Physiol., 292, F1771-F1781, 2007.

Grela, E. R., Sobolewska S., and Roziński T.: Effect of inulin extracts or inulin-containing plant supplement on blood lipid indices and fatty acid profile in fattener tissues, Pol. J.Vet. Sci., 17, 93-98, 2014.

Groenestege, W. M., Hoenderop, J. G., van den Heuvel, L., Knoers, N., and Bindels, R. J.: The epithelial $\mathrm{Mg}^{2+}$ channel transient receptor potential melastatin 6 is regulated by dietary $\mathrm{Mg}^{2+}$ content and estrogens, J. Am. Soc. Nephrol., 17, 1035-1043, 2006.

Hsu, Y. J., Hoenderop, J. G., Bindels, and R. J.: TRP channels in kidney disease, Biochim. Biophys. Acta., 1772, 928-936, 2007.

Jahnen-Dechent, W. and Ketteler, M.: Magnesium basics, Clin. Kidney J, 5, I3i14, doi:10.1093/ndtplus/sfr163, 2012.

Kaneko, J. J., Harvey, J. W., and Bruss, M. L.: Clinical Biochemistry of Domestic Animals, Appendix VIII Blood Analyte Reference Values in Large Animals, 6th Ed. Academic Press, San Diego, 2008.

Konrad, M., Schlingmann, K. P., and Gudermann, T.: Insights into the molecular nature of magnesium homeostasis, Am. J. Physiol. Renal. Physiol., 286, F599-605, 2004.

Li, M., Jiang, J., and Yue, L.: Functional characterization of homoand heteromeric channel kinases TRPM6 and TRPM7, J. Gen. Physiol., 127, 525-537, 2006.

Lipiński, K., Stasiewicz, M., Purwin, C., and Żuk-Gołaszewska, K.: Effects of magnesium on pork quality, J. Elem., 16, 325-337, 2011.

Luo, W., Li, Z., Huang, Y., Han, Y., Yao, C., Duan, X., Ouyang, H., and Li, L.: Generation of AQP2-Cre transgenic mini-pigs specifically expressing Cre recombinase in kidney collecting duct cells, Transgenic Res., 23, 365-375, 2014.

Mandel, N. S., Henderson Jr., J. D., Hung, L. Y., Wille, D. F., and Wiessner, J. H.: A porcine model of calcium oxalate kidney stone disease, J. Urol., 171, 1301-1303, 2004.

Mayo, R. H., Plumlee, M. P., and Beeson, W. M.: Magnesium requirement of the pig, J. Anim. Sci., 18, 264-273, 1959.

Muallem, S. and Moe, O. W.: When EGF is offside, magnesium is wasted, J. Clin. Invest., 117, 2086-2089, 2007.

Ozg, M., Bayle, D., Zimowska, W., and Mazur, A.: Effect of a low magnesium diet on magnesium status and gene expression in the kidneys of mice selected for high and low magnesium erythrocyte levels. Magnes Res., 20, 148-153, 2007.

Pham, P. C., Pham, P. A., Pham, S. V., Pham, P. T., Pham, P. M., and Pham, P. T.: Hypomagnesemia: a clinical perspective, Int. J. Nephrol. Renovasc. Dis., 9, 7, 219-230, 2014.

Quamme, G. A.: Recent developments in intestinal magnesium absorption, Curr. Opin. Gastroenterol., 24, 230-235, 2008.

Quamme, G. A. and de Rouffignac, C.: Epithelial magnesium transport and regulation by the kidney, Front. Biosci., 1, D694-711, 2000 .
Roberfroid, M. B.: Introducing inulin-type fructans, Br. J. Nutr., 93, S13-25, 2005a.

Roberfroid, M. B.: Inulin-type fructans: functional food ingredients, CRC Press, Boca Raton, FL, 2005b.

Roberfroid, M. B.: Inulin-type fructans: functional food ingredients, J. Nutr., 137, 2493-2502, 2007.

Romani, A. M.: Cellular magnesium homeostasis, Arch. Biochem. Biophy., 512, 1-23, 2011.

Rondón, L. J., Groenestege, W. M., Rayssiguier, Y., and Mazur, A.: Relationship between low magnesium status and TRPM6 expression in the kidney and large intestine, Am. J. Physiol. Regul. Integr. Comp. Physiol., 294, R2001-2007, 2008a.

Rondón, L. J., Rayssiguier, Y., and Mazur, A.: Dietary inulin in mice stimulates $\mathrm{Mg}^{2+}$ absorption and modulates TRPM6 and TRPM7 expression in large intestine and kidney, Magnes. Res., 21, 224 231, 2008b.

Samanta, A. K., Jayapal, N., Senani, S., Kolte, A. P., and Sridhar, M.: Prebiotic inulin: Useful dietary adjuncts to manipulate the livestock gut microflora, Braz. J. Microbiol., 44, 1-14, 2013.

Sampaio, F. J., Pereira-Sampaio, M. A., Favorito, L. A.: The pig kidney as an endourologic model: anatomic contribution, J. Endourol., 12, 45-50, 1998.

Schlingmann, K. P. and Gudermann, T.: A critical role of TRPM channel-kinase for human magnesium transport, J. Physiol., 15, 301-308, 2005.

Schlingmann, K. P., Weber, S., Peters, M., Niemann Nejsum, L., Vitzthum, H., Klingel, K., Kratz, M., Haddad, E., Ristoff, E., Dinour, D., Syrrou, M., Nielsen, S., Sassen, M., Waldegger, S., Seyberth, H. W., and Konrad, M.: Hypomagnesemia with secondary hypocalcemia is caused by mutations in TRPM6, a new member of the TRPM gene family, Nat. Genet., 31, 166-170, 2002.

Schlingmann, K. P., Waldegger, S., Konrad, M., Chubanov, V., and Gudermann, T.: TRPM6 and TRPM7-Gatekeepers of human magnesium metabolism, Biochim. Biophys. Acta, 1772, 813821, 2007.

Scholz-Ahrens, K. E., Schaafsma, G., van den Heuvel, E. G., and Schrezenmeir, J.: Effects of prebiotics on mineral metabolism, Am. J. Clin. Nutr., 73, 459S-464S, 2001.

Seo, J. W. and Park, T. J.: Magnesium metabolism, Electrolyte Blood Press, 6, 86-95, 2008.

Tahiri, M., Tressol, J. C., Arnaud, J., Bornet, F., BouteloupDemange, C., Feillet-Coudray, C., Ducros, V., Pépin, D., Brouns, F., Rayssiguier, A. M., and Coudray, C.: Five-week intake of short-chain fructo-oligosaccharides increases intestinal absorption and status of magnesium in postmenopausal women, J. Bone Miner. Res., 16, 2152-2160, 2001.

Van Angelen, A. A., San-Cristobal, P., Pulskens, W. P., Hoenderop, J. G., and Bindels, R. J.: The impact of dietary magnesium restriction on magnesiotropic and calciotropic genes, Nephrol. Dial. Transplant., 28, 2983-2993, 2013.

Van der Wijst, J., Bindels, R. J., and Hoenderop, J. G.: $\mathrm{Mg}^{2+}$ homeostasis: the balancing act of TRPM6, Curr. Opin. Nephrol. Hypertens., 23, 361-369, 2014.

Verdonk J. M., Shim S. B., van Leeuwen P., and Verstegen M. W.: Application of inulin-type fructans in animal feed and pet food, Br. J. Nutr., 93, 125-138, 2005.

Voets, T., Nilius, B., Hoefs, S., van der Kemp, A. W., Droogmans, G., Bindels, R. J., and Hoenderop, J. G.: TRPM6 forms the $\mathrm{Mg}^{2+}$ 
influx channel involved in intestinal and renal $\mathrm{Mg}^{2+}$ absorption, J. Biol. Chem., 279, 19-25, 2004.

Xie, J., Sun, B., Du, J., Yang, W., Chen, H. C., Overton, J. D., Runnels, L. W., and Yue, L.: Phosphatidylinositol 4,5-bisphosphate (PIP(2)) controls magnesium gatekeeper TRPM6 activity, Sci. Rep., 1, 146, 2011.

Xu Ch., Chen X., Ji Ch., Ma Q., and Hao K.: Study of the Application of Fructooligosaccharides in Piglets, Asian-Aust. J. Anim. Sci., 18, 1011-1016, 2005.

Yasuda, K., Roneker, K. R., Miller, D. D., Welch, R. M., and Lei, X. G.: Supplemental dietary inulin affects the bioavailability of iron in corn and soybean meal to young pigs, J. Nutr., 136, 30333038, 2006.
Yoshiki Nishizawa, M. D., Hirotoshi Morii, M. D., and Jean Durlach, M. D.: New Perspectives in Magnesium Research. Significance of Magnesium in Animals, Tohru Matsui, Springer, 381-391, 2007.

Younes, H., Coudray, C., Bellanger, J., Demigné, C., Rayssiguier, Y., and Rémésy, C.: Effects of two fermentable carbohydrates (inulin and resistant starch) and their combination on calcium and magnesium balance in rats, Br. J. Nutr., 86, 479-485, 2001. 